\title{
Paeoniflorin inhibits PDGF-BB-induced human airway smooth muscle cell growth and migration
}

\author{
HONG ZHOU ${ }^{1}$, QI WU ${ }^{2}$, LUQING WEI ${ }^{3}$ and SHOUCHUN PENG ${ }^{3}$ \\ ${ }^{1}$ Graduate School of Tianjin Medical University, Tianjin 300070; ${ }^{2}$ Department of Respiration, \\ Tianjin Medical University General Hospital, Tianjin 300052; ${ }^{3}$ Department of Respiratory and Critical Care Medicine, \\ The Affiliated Hospital of Logistics University of Chinese People's Armed Police Force, Tianjin 300162, P.R. China
}

Received April 23, 2016; Accepted March 21, 2017

DOI: $10.3892 / \mathrm{mmr} .2017 .8180$

\begin{abstract}
Abnormal proliferation and migration of airway smooth muscle cells (ASMCs) is important in the progression of asthma. Paeoniflorin (PF), one of the major active ingredients of Paeonia lactiflora, has been reported to exhibit anti-asthmatic effects. However, the effects of $\mathrm{PF}$ in the regulation of platelet-derived growth factor (PDGF)-BB-induced ASMC proliferation and migration remain unknown. The present study was designed to investigate the effects of PF on human ASMCs and the underlying mechanism. The results demonstrated that $\mathrm{PF}$ treatment significantly reduced the numbers of live ASMC cells and their PDGF-BB-induced migration. PF treatment also suppressed PDGF-BB-induced $\alpha$-smooth muscle actin expression in ASMCs. Furthermore, pretreatment with PF reduced PDGF-BB-induced phosphorylation of phosphoinositide 3-kinase (PI3K) and AKT serine/threonine kinase 1 (Akt) in ASMCs. In conclusion, the present study demonstrated for the first time that PF inhibited ASMC growth and migration induced by PDGF-BB, and that this effect may be partly due to inhibition of the PI3K/Akt signaling pathway. The results provide novel information regarding the role of $\mathrm{PF}$ as a potential therapeutic agent for the treatment of asthma.
\end{abstract}

\section{Introduction}

Asthma is a chronic inflammatory disease of the lower airway, and its prevalence continues to increase in the past 20 years (1). Asthma is characterized by airflow obstruction, airway inflammation and airway remodeling (2). Despite many studies focusing on the pathogenesis of asthma, the underlying mechanisms remain unclear. Airway smooth muscle is a major

Correspondence to: Professor Qi Wu, Department of Respiration, Tianjin Medical University General Hospital, 154 Anshan Road, Tianjin 300052, P.R. China

E-mail: resp_wuqi@163.com

Key words: airway smooth muscle cells, platelet-derived growth factor-BB, cell growth, migration component of the remodeled airway in patients with asthma (3). Previous studies demonstrated that abnormal proliferation and migration of airway smooth muscle cells (ASMCs) is important in the pathogenesis of asthma (4,5). In addition, platelet-derived growth factor (PDGF)-BB has been reported to induce ASMC proliferation and migration (6,7), and elevated PDGF-BB expression is correlated with the severity of the disease (8). Therefore, inhibiting PDGF-BB-induced ASMC proliferation and migration may provide a novel therapeutic method for asthma.

Paeoniflorin (PF) is one of the major active ingredients of Paeonia lactiflora. There is substantial evidence that PF exhibits anti-inflammatory, antitumor, immunoregulatory, and nerve protective effects (9-12). For example, PF treatment significantly suppresses proliferation and invasion in human breast cancer cells (13). Recently, Sun et al (14) reported that $\mathrm{PF}$ oral administration in asthmatic mice markedly reduced airway hyperresponsiveness to aerosolized methacholine and decreased interleukin (IL)-5, IL-13, IL-17 and eotaxin levels in bronchoalveolar lavage fluid. However, the effects of PF on PDGF-BB-induced ASMC proliferation and migration remain unknown. The present study was designed to investigate the effects of PF treatment on human ASMCs and the underlying mechanism.

\section{Materials and methods}

Cell culture. The human ASMC line was purchased from the American Type Culture Collection (ATCC; Manassas, VA, USA) and cultured in DMEM (Invitrogen; Thermo Fisher Scientific, Inc., Waltham, MA, USA) medium containing $10 \%$ fetal bovine serum (FBS; Hyclone; GE Healthcare Life Sciences, Logan, UT, USA), $100 \mathrm{U} / \mathrm{ml}$ penicillin and $100 \mathrm{mg} / \mathrm{ml}$ streptomycin (Sigma-Aldrich; Merck KGaA, Darmstadt, Germany) in a humidified atmosphere of $5 \% \mathrm{CO}_{2}$ at $37^{\circ} \mathrm{C}$. ASMCs in passages 9-20 were used for the experiments presented in this study.

Cell viability assay. Cell viability was measured using an MTT assay. In brief, ASMCs at a density of $1 \times 10^{4}$ cells/well were seeded in a 96-well plate and grown in DMEM medium containing $10 \%$ FBS for $24 \mathrm{~h}$. ASMCs were pretreated with PF (10, 20 and 40 nM; Sigma-Aldrich; Merck KGaA) for $1 \mathrm{~h}$ prior to stimulation with PDGF-BB (10 ng/ml; Sigma-Aldrich; 
Merck KGaA) for 24, 48 or $72 \mathrm{~h}$. Then, MTT $(5 \mathrm{mg} / \mathrm{ml}$; Sigma-Aldrich; Merck KGaA) was added to each well and incubated for $4 \mathrm{~h}$ at $37^{\circ} \mathrm{C}$ in $5 \% \mathrm{CO}_{2}$. Subsequently, the supernatants were removed, and $150 \mu$ l of dimethyl sulfoxide was added to dissolve the formazan crystals. The absorbance at $450 \mathrm{~nm}$ was measured using a Spectra Max 190 microplate reader (Molecular Devices, LLC, Sunnyvale, CA, USA).

Cell migration assay. Cell migration was examined using transwell chambers. In brief, following treatment as described above, ASMCs at a density of $5 \times 10^{4}$ cells/well suspended in $0.1 \%$ FBS medium were added into the upper chamber. DMEM medium (500 $\mu \mathrm{l}$ ) containing $10 \% \mathrm{FBS}$, with or without PDGF-BB, was added into the lower chamber. Following incubation at $37^{\circ} \mathrm{C}$ for $24 \mathrm{~h}$, cells migrated to the lower surface of the transwell membrane were stained with hematoxylin and eosin (Sigma-Aldrich; Merck KGaA), and the mean number of cells per four fields of view was counted under a light microscope. Migration was measured as the number of cells/field.

RNA extraction and reverse transcription-quantitative polymerase chain reaction $(R T-q P C R)$. Total RNA was extracted from ASMCs using TRIzol reagent (Invitrogen; Thermo Fisher Scientific, Inc.), according to the manufacturer's instructions. cDNA was synthesized from the extracted RNA (3 $\mu \mathrm{g}$ ) using the SuperScript First-Strand cDNA Synthesis SuperMix kit (Invitrogen; Thermo Fisher Scientific, Inc.). qPCR analysis was performed using a 7500 Real-Time PCR System (Applied Biosystems; Thermo Fisher Scientific, Inc.) with Fast Start Universal SYBR Green Master mix (Roche Diagnostics, Basel, Switzerland). The specific primers were: $\alpha$-smooth muscle actin ( $\alpha$-SMA) sense, 5'-CTATTCCTTCGT GACTACT-3' and antisense, 5'-ATGCTGTTATAGGTGGTG GTT-3'; $\beta$-actin sense, 5'-TTAGTTGCGTTACACCCTTTC-3' and antisense, 5'-ACCTTCACCGTTCCAGTTT-3'. The PCR cycling program was $95^{\circ} \mathrm{C}$ for $3 \mathrm{~min}$, then 35 cycles of $94^{\circ} \mathrm{C}$ for $20 \mathrm{sec}, 59^{\circ} \mathrm{C}$ for $30 \mathrm{sec}$ and $72^{\circ} \mathrm{C}$ for $20 \mathrm{sec}$, and a final extension at $72^{\circ} \mathrm{C}$ for $5 \mathrm{~min}$. $\beta$-actin was used as a normalization control and the results were analyzed by the method of $2^{-\Delta \Delta c q}(15)$

Western blot analysis. ASMCs were washed with PBS and lysed using radioimmunoprecipitation assay lysis buffer (Beyotime Institute of Biotechnology, Nantong, China). The cell lysate supernatants were harvested by centrifugation at $10,000 \times \mathrm{g}$ for $10 \mathrm{~min}$ at $4^{\circ} \mathrm{C}$. The protein concentration was determined using a Bradford protein assay. Equal amounts of protein $(30 \mu \mathrm{g})$ were separated by $10 \%$ SDS-PAGE and transferred onto polyvinylidene fluoride membranes (Sigma-Aldrich; Merck KGaA). Following blocking with 5\% skim milk in Tris-buffered saline (TBS) with $0.1 \%$ Tween-20 at room temperature for $1 \mathrm{~h}$, the membranes were incubated overnight at $4^{\circ} \mathrm{C}$ with primary antibodies targeting $\alpha$-SMA (1:2,500; cat. no. sc-53142), phosphoinositide 3-kinase (PI3K, 1:2,000; cat. no. sc-365290), phosphorylated (p)-PI3K (1:2,500; sc-293115), AKT serine/threonine kinase 1 (Akt; (1:1,000; cat. no. sc-5298), p-Akt (1:1,000; cat. no. sc-52940) and GAPDH (1:3,000, cat. no. sc-59540; Santa Cruz Biotechnology, Inc., Dallas, TX, USA). Then, the membranes were washed with TBS containing $0.1 \%$ Tween for $10 \mathrm{~min}$ and incubated with

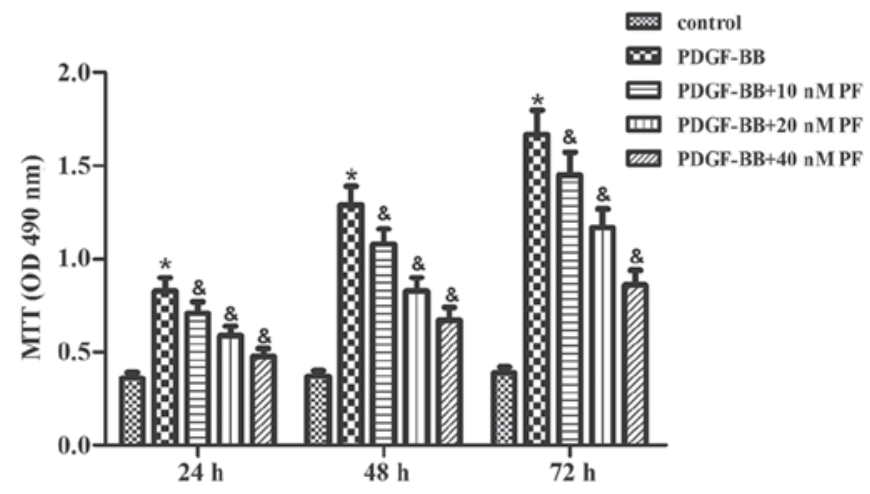

Figure 1. PF pretreatment suppresses PDGF-BB-induced ASMC growth. ASMCs were pretreated with PF $(10,20$ or $40 \mathrm{nM})$ for $1 \mathrm{~h}$ prior to stimulation with PDGF-BB (10 ng/ml) for 24,48 or $72 \mathrm{~h}$. Untreated cells were used as control. Cell viability was measured with the MTT assay and reported as absorbance at $490 \mathrm{~nm}$. Results are presented as mean + standard deviation of three independent experiments performed in triplicate. ${ }^{*} \mathrm{P}<0.05$ vs. control group; ${ }^{\circledR} \mathrm{P}<0.05$ vs. $\mathrm{PDGF}-\mathrm{BB}$ group. $\mathrm{PF}$, paeoniflorin; $\mathrm{PDGF}-\mathrm{BB}$, platelet-derived growth factor-BB; ASMC, airway smooth muscle cells; OD, optical density.

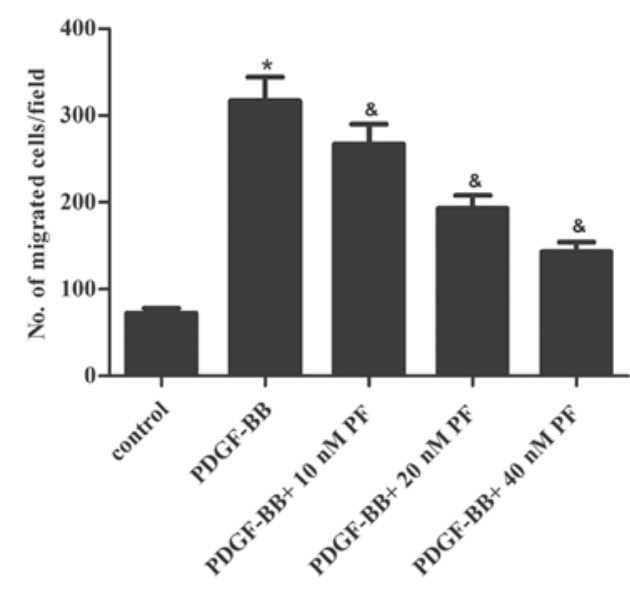

Figure 2. PF pretreatment suppresses PDGF-BB-induced ASMC migration. ASMCs were pretreated with $\mathrm{PF}(10,20$ or $40 \mathrm{nM})$ for $1 \mathrm{~h}$ prior to stimulation with PDGF-BB (10 ng/ml) for $24 \mathrm{~h}$. Untreated cells were used as control. Cell migration was examined usingTranswell migration chambers. Results are presented as mean \pm standard deviation obtained from three independent experiments performed in triplicate. ${ }^{*} \mathrm{P}<0.05 \mathrm{vs}$. control group; ${ }^{\&} \mathrm{P}<0.05$ vs. PDGF-BB group. PF, paeoniflorin; PDGF-BB, platelet-derived growth factor-BB; ASMC, airway smooth muscle cells.

horseradish peroxidase-conjugated secondary antibodies (1:2,500, cat. no. sc-2005; Santa Cruz Biotechnology, Inc.) for $1 \mathrm{~h}$ at room temperature. Protein bands were evaluated by enhanced chemiluminescence (Thermo Fisher Scientific, Inc.). The optical densities of the bands were quantified using Gel-Pro Analyzer v4.0 (Media Cybernetics, Inc., Rockville, MD, USA).

Data analysis. The results were analyzed using SPSS software version 13.0 (SPSS, Inc., Chicago, IL, USA). All experiments were performed at least in triplicate and results are expressed as mean \pm standard deviation. Statistical significance was analyzed with the one-way analysis of variance or the Student's two-tailed t-test followed by Tukey's post hoc test. $\mathrm{P}<0.05$ was considered to indicate a statistically significant difference. 
A

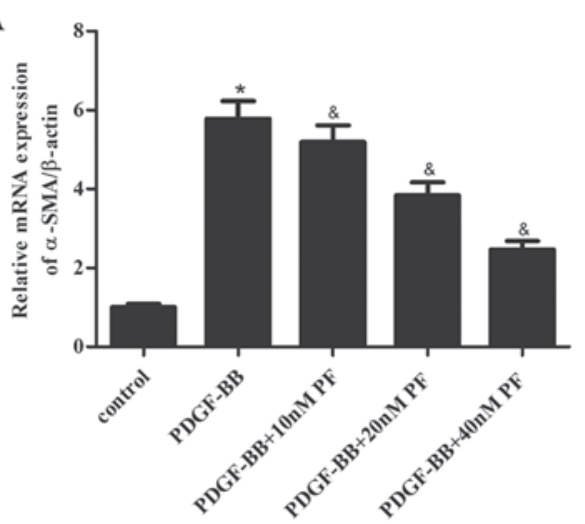

B
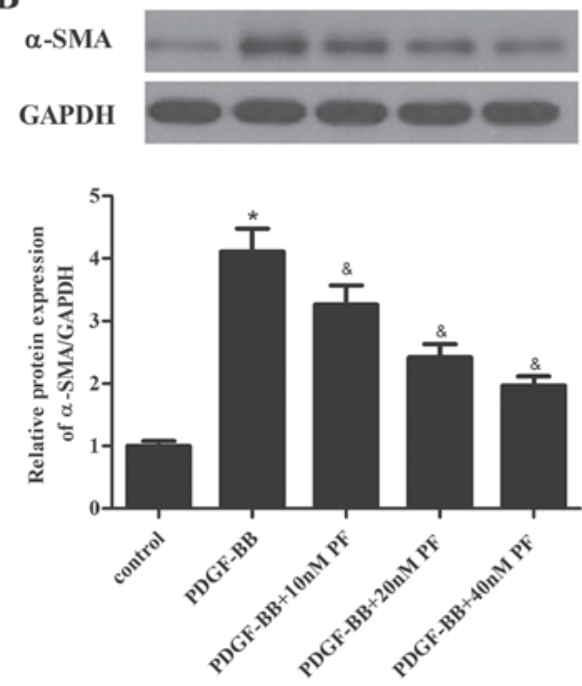

Figure 3. PF pretreatment suppresses PDGF-BB-induced $\alpha$-SMA expression in ASMCs. ASMCs were pretreated with $\mathrm{PF}(10,20$ or $40 \mathrm{nM})$ for $1 \mathrm{~h}$ prior to stimulation with PDGF-BB $(10 \mathrm{ng} / \mathrm{ml})$ for $24 \mathrm{~h}$. Untreated cells were used as control. (A) $\alpha$-SMA mRNA expression levels were detected by reverse transcription-quantitative polymerase chain reaction. (B) $\alpha$-SMA protein expression levels were detected by western blotting. Results are presented as mean \pm standard deviation of three independent experiments performed in triplicate. ${ }^{*} \mathrm{P}<0.05$ vs. control group; ${ }^{\&} \mathrm{P}<0.05$ vs. $\mathrm{PDGF}-\mathrm{BB}$ group. $\mathrm{PF}$, paeoniflorin; PDGF-BB, platelet-derived growth factor-BB; $\alpha$-SMA, $\alpha$-smooth muscle actin; ASMC, airway smooth muscle cells.

\section{Results}

PF treatment suppresses PDGF-BB-induced ASMC growth. First, the effect of PF treatment on ASMC growth was examined using the MTT assay. As indicated in Fig. 1, PDGF-BB stimulation significantly induced growth in ASMCs over the course of $72 \mathrm{~h}$, compared with the control group. However, the PDGF-BB-induced effect on ASMC growth was inhibited by $\mathrm{PF}$ pretreatment in a concentration-dependent manner (Fig. 1).

PF treatment suppresses PDGF-BB-induced ASMC migration. ASMC migration is hypothesized to be a key event in the pathogenesis of asthma (16). Thus, the effect of PF treatment on ASMC migration in response to PDGF-BB stimulation was examined. The results of transwell migration assays demonstrated that stimulation with PDGF-BB greatly promoted the migration of ASMCs, compared with the control group (Fig. 2). However, PF pretreatment partially reversed this effect in a dose-dependent manner (Fig. 2).
A

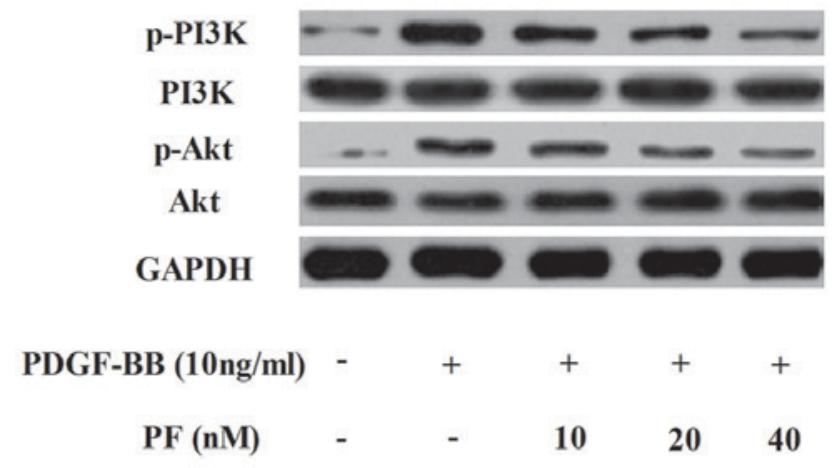

B

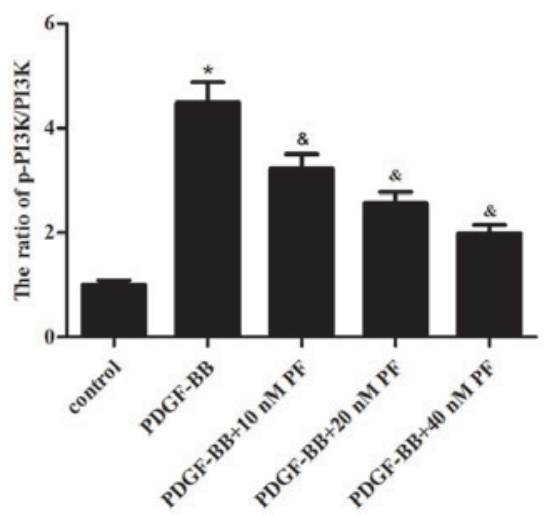

C

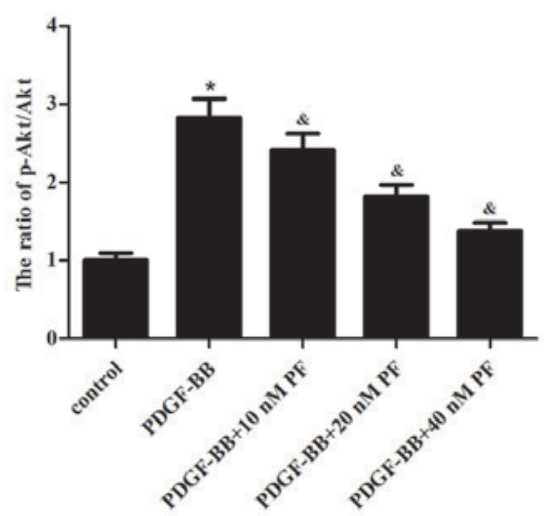

Figure 4. PF pretreatment inhibits PDGF-BB-induced phosphorylation of PI3K and Akt in ASMCs. ASMCs were pretreated with PF $(10,20$ or $40 \mathrm{nM})$ for $1 \mathrm{~h}$ prior to stimulation with PDGF-BB $(10 \mathrm{ng} / \mathrm{ml})$ for $24 \mathrm{~h}$. Untreated cells were used as control. The expression of p-PI3K, PI3K, p-Akt and Akt proteins was detected by western blotting. (A) Representative blots. (B) Quantification of the p-PI3K to PI3K ratio. (C) Quantification of the p-Akt to Akt ratio. Results are presented as the mean \pm standard deviation of three independent experiments performed in triplicate. ${ }^{*} \mathrm{P}<0.05 \mathrm{vs}$. control group; ${ }^{\circledR} \mathrm{P}<0.05$ vs. PDGF-BB group. PF, paeoniflorin; PDGF-BB, platelet-derived growth factor-BB; PI3K, phosphoinositide 3-kinase; Akt, AKT serine/threonine kinase 1; ASMC, airway smooth muscle cells; p, phosphorylated.

PF treatment suppresses PDGF-BB-induced $\alpha$-SMA expression in ASMCs. $\alpha$-SMA is a major constituent of the contractile apparatus of ASMCs, and its expression has been associated to the progression of asthma (17). Therefore, the effect of PF treatment on $\alpha$-SMA expression in ASMCs was investigated. As demonstrated in Fig. 3A, PDGF-BB stimulation in ASMCs significantly increased the mRNA expression levels of $\alpha$-SMA, compared with the control group. However, PF pretreatment 
partially inhibited the PDGF-BB-induced $\alpha$-SMA mRNA overexpression (Fig. 3A). Similarly, the results of western blot analysis demonstrated that PF pretreatment suppressed PDGF-BB-induced $\alpha$-SMA protein overexpression in ASMCs, compared with cells treated with PDGF-BB alone (Fig. 3B).

PF treatment inhibits PDGF-BB-induced phosphorylation of $P I 3 K$ and Akt in ASMCs. To explore the signaling mechanisms involved in the effects of PF on ASMC growth and migration, the phosphorylation status of PI3K and Akt was investigated by western blotting. As demonstrated in Fig. 4, PDGF-BB stimulation significantly activated $\mathrm{PI} 3 \mathrm{~K}$ and Akt phosphorylation in ASMCs compared with the control group. This activation was partially reversed by PF pretreatment, with phosphorylation levels for both PI3K and Akt significantly reduced compared with cells treated with PDGF-BB alone (Fig. 4).

\section{Discussion}

Abnormal proliferation and migration of ASMCs is involved in the progression of asthma (18). The present results demonstrated that PF treatment significantly inhibited PDGF-BB-induced ASMC growth and migration. PF pretreatment also suppressed PDGF-BB-induced $\alpha$-SMA expression in ASMCs. Finally, PF pretreatment reduced PDGF-BB-induced phosphorylation of PI3K and Akt in ASMCs.

ASMCs obtained from asthmatic patients proliferate faster in culture than those obtained from non-asthmatic subjects (19). It has been reported that PF inhibits the proliferation of lung cancer A549 cells by blocking cell cycle progression in the G0/G1 phase (20). PF has also been demonstrated to be effective in the treatment of lung fibrosis in animal models (21). In the present study, PF treatment significantly inhibited PDGF-BB-induced growth of ASMCs, suggesting that PF may attenuate asthma progression via suppressing ASMC proliferation.

In addition, increased migration of ASMCs is thought to participate in the progression of asthma. ASMCs from patients with asthma exhibit more migratory capabilities compared with cells from normal subjects (22). A growing body of evidence indicates that PDGF-BB is a potent chemoattractant that induces ASMC migration (23-25). Thus, inhibition of ASMC migration represents a potentially important therapeutic strategy for the treatment of asthma. In the present study, PDGF-BB stimulation significantly induced ASMC migration, while PF pretreatment significantly inhibited this PDGF-BB-induced migration effect in ASMCs.

ASMC phenotypic switching (contractile to synthetic) is a critical mediator of airway remodeling in asthma. The phenotypic modulation of ASMCs contributes to the pathology of asthma by altering proliferation, secretion of inflammatory mediators and matrix deposition $(26,27)$. It has been reported that increased levels of $\alpha$-SMA facilitate ASMC proliferation and migration, which are important for asthma progression (28). In vitro PDGF-BB stimulation induces ASMC phenotypic switching $(29,30)$. PF treatment has been demonstrated to decrease the contents of hydroxyproline, type I collagen and $\alpha$-SMA in lung tissues of bleomycin-induced pulmonary fibrosis (31). In the present study, PF pretreatment suppressed PDGF-BB-induced $\alpha$-SMA expression in
ASMCs, suggesting that PF may attenuate ASMC hyperplasia and hypertrophy.

PDGF-BB has been reported to stimulate proliferation and migration in ASMCs through PI3K signaling, which in turn activates Akt signaling (32). Inhibition of PI3K/Akt signaling significantly inhibits ASMC proliferation and migration $(33,34)$. Furthermore, Zheng et al (35) reported that PF significantly inhibits the expression of PI3K, Akt, p-Akt and p-signal transducer and activator of transcription 3 in human gastric carcinoma MGC-803 cells, while a PI3K agonist (insulin-like growth factor 1) reverses the effect of PF on MGC-803 cell proliferation. In the present study, PDGF-BB treatment significantly activated PI3K and Akt phosphorylation in ASMCs. The present results are consistent with previous studies reporting that PI3K/Akt signaling mediates ASMC proliferation and migration induced by PDGF-BB. However, in the present study, PF pretreatment significantly suppressed PDGF-BB-induced phosphorylation of PI3K and Akt. These data suggest that PF inhibited PDGF-BB-induced human ASMC growth and migration through suppressing the activation of the PI3K/Akt signaling pathway.

In conclusion, the present study demonstrated for the first time that PF inhibited ASMC growth and migration induced by PDGF-BB. The inhibitory effect involved, at least partly, inhibition of the PI3K/Akt signaling pathway. Therefore, the present results provide evidence that PF may serve as a potential therapeutic agent for the treatment of asthma in the future.

\section{References}

1. Barros R, Moreira A, Padrão P, Teixeira VH, Carvalho P, Delgado L, Lopes C, Severo M and Moreira P: Dietary patterns and asthma prevalence, incidence and control. Clin Exp Allergy 45: 1673-1680, 2015.

2. Halwani R, Al-Muhsen S and Hamid Q: Airway remodeling in asthma. Curr Opin Pharmacol 10: 236-245, 2010.

3. Bara I, Ozier A, Tunon de Lara JM, Marthan R and Berger P: Pathophysiology of bronchial smooth muscle remodelling in asthma. Eur Respir J 36: 1174-1184, 2010.

4. Madison JM: Migration of airway smooth muscle cells. Am J Respir Cell Mol Biol 29: 8-11, 2003.

5. Hirst SJ, Martin JG, Bonacci JV, Chan V, Fixman ED, Hamid QA, Herszberg B, Lavoie JP, McVicker CG, Moir LM, et al: Proliferative aspects of airway smooth muscle. J Allergy Clin Immunol 114 (Suppl 2): S2-S17, 2004.

6. Spinelli AM, González-Cobos JC, Zhang X, Motiani RK, Rowan S, Zhang W, Garrett J, Vincent PA, Matrougui K, Singer HA and Trebak M: Airway smooth muscle STIM1 and Orail are upregulated in asthmatic mice and mediate PDGF-activated SOCE, CRAC currents, proliferation, and migration. Pflugers Arch 464: 481-492, 2012.

7. Ito I, Fixman ED, Asai K, Yoshida M, Gounni AS, Martin JG and Hamid Q: Platelet-derived growth factor and transforming growth factor-beta modulate the expression of matrix metalloproteinases and migratory function of human airway smooth muscle cells. Clin Exp Allergy 39: 1370-1380, 2009.

8. Ohno I, Nitta Y, Yamauchi K, Hoshi H, Honma M, Woolley K, O'Byrne P, Dolovich J, Jordana M, Tamura G, et al: Eosinophils as a potential source of platelet-derived growth factor B-chain (PDGF-B) in nasal polyposis and bronchial asthma. Am J Respir Cell Mol Biol 13: 639-647, 1995.

9. Kim ID and Ha BJ: Paeoniflorin protects RAW 264.7 macrophages from LPS-induced cytotoxicity and genotoxicity. Toxicol In Vitro 23: 1014-1019, 2009.

10. Wang H, Zhou H, Wang CX, Li YS, Xie HY, Luo JD and Zhou Y: Paeoniflorin inhibits growth of human colorectal carcinoma HT 29 cells in vitro and in vivo. Food Chem Toxicol 50: 1560-1567, 2012. 
11. Zhang T, Yang Z, Yang S, Du J and Wang S: Immunoregulatory effects of paeoniflorin exerts anti-asthmatic effects via modulation of the Th1/Th2 equilibrium. Inflammation 38: 2017-2025, 2015.

12. Li J, Xiong X and Liu Y: Protective effect of paeoniflorin against optic nerve crush. J Huazhong Univ Sci Technolog Med Sci 27: 650-652, 2007.

13. Zhang Q, Yuan Y, Cui J, Xiao T and Jiang D: Paeoniflorin inhibits proliferation and invasion of breast cancer cells through suppressing Notch-1 signaling pathway. Biomed Pharmacother 78: 197-203, 2016.

14. Sun J, Wu J, Xu C, Luo Q, Li B and Dong J: Paeoniflorin attenuates allergic inflammation in asthmatic mice. Int Immunopharmacol 24: 88-94, 2015.

15. Livak KJ and Schmittgen TD: Analysis of relative gene expression data using real-time quantitative PCR and the 2(-Delta Delta C(T)) method. Methods 25: 402-408, 2001.

16. Joubert P, Lajoie-Kadoch S, Labonté I, Gounni AS, Maghni K Wellemans V, Chakir J, Laviolette M, Hamid Q and Lamkhioued B: CCR3 expression and function in asthmatic airway smooth muscle cells. J Immunol 175: 2702-2708, 2005.

17. Qiu C, Zhang J, Su M and Fan X: Nuclear factor-kB mediates the phenotype switching of airway smooth muscle cells in a murine asthma model. Int J Clin Exp Pathol 8: 12115-12128, 2015.

18. Wei Y, Xu YD, Yin LM, Wang Y, Ran J, Liu Q, Ma ZF, Liu YY and Yang YQ: Recombinant rat CC10 protein inhibits PDGF-induced airway smooth muscle cells proliferation and migration. Biomed Res Int 2013: 690937, 2013.

19. Michaeloudes C, Chang PJ, Petrou M and Chung KF: Transforming growth factor- $\beta$ and nuclear factor E2-related factor 2 regulate antioxidant responses in airway smooth muscle cells: Role in asthma. Am J Respir Crit Care Med 184: 894-903, 2011.

20. Hung JY, Yang CJ, Tsai YM, Huang HW and Huang MS: Antiproliferative activity of paeoniflorin is through cell cycle arrest and the Fas/Fas ligand-mediated apoptotic pathway in human non-small cell lung cancer A549 cells. Clin Exp Pharmacol Physiol 35: 141-147, 2008.

21. Ji Y, Wang T, Wei ZF, Lu GX, Jiang SD, Xia YF and Dai Y: Paeoniflorin, the main active constituent of Paeonia iactiflora roots, atteunates bleomycin-induced pulmonary fibrosis in mice by suppressing the synthesis of type I collagen. J Ethnopharmacol 149: 825-832, 2013.

22. Parameswaran K, Radford K, Fanat A, Stephen J, Bonnans C, Levy BD, Janssen LJ and Cox PG: Modulation of human airway smooth muscle migration by lipid mediators and Th-2 cytokines. Am J Respir Cell Mol Biol 37: 240-247, 2007.

23. Ning Y, Huang H, Dong Y, Sun Q, Zhang W, Xu W and Li Q: 5-Aza-2'-deoxycytidine inhibited PDGF-induced rat airway smooth muscle cell phenotypic switching. Arch Toxicol 87: 871-881, 2013
24. Liu W, Kong H, Zeng X, Wang J, Wang Z, Yan X, Wang Y, Xie W and Wang H: Iptakalim inhibits PDGF-BB-induced human airway smooth muscle cells proliferation and migration. Exp Cell Res 336: 204-210, 2015.

25. Xu YD, Wei Y, Wang Y, Yin LM, Park GH, Liu YY and Yang YQ: Exogenous S100A8 protein inhibits PDGF-induced migration of airway smooth muscle cells in a RAGE-dependent manner. Biochem Biophys Res Commun 472: 243-249, 2016.

26. Hirst SJ, Walker TR and Chilvers ER: Phenotypic diversity and molecular mechanisms of airway smooth muscle proliferation in asthma. Eur Respir J 16: 159-177, 2000.

27. Moir LM, Leung SY, Eynott PR, McVicker CG, Ward JP, Chung KF and Hirst SJ: Repeated allergen inhalation induces phenotypic modulation of smooth muscle in bronchioles of sensitized rats. Am J Physiol Lung Cell Mol Physiol 284: L148-L159, 2003.

28. Xu GN, Yang K, Xu ZP, Zhu L, Hou LN, Qi H, Chen HZ and Cui YY: Protective effects of anisodamine on cigarette smoke extract-induced airway smooth muscle cell proliferation and tracheal contractility. Toxicol Appl Pharmacol 262: 70-79, 2012.

29. Dekkers B, Prins A, Oldenbeuving G, Pool K, Elzinga C, Meurs H, Schmidt $M$ and Roscioni S: Epac and PKA inhibit PDGF-induced airway smooth muscle phenotype modulation. Am J Respir Crit Care Med 181: A2142, 2010.

30. Carlin SM, Roth $\mathrm{M}$ and Black JL: Urokinase potentiates PDGF-induced chemotaxis of human airway smooth muscle cells. Am J Physiol Lung Cell Mol Physiol 284: L1020-L1026, 2003.

31. Ma J and Jemal A: Breast cancer statistics. In: Breast Cancer Metastasis and Drug Resistance. Springer, New York, pp1-18, 2013.

32. Chiou YL, Shieh JJ and Lin CY: Blocking of Akt/NF-kappaB signaling by pentoxifylline inhibits platelet-derived growth factor-stimulated proliferation in Brown Norway rat airway smooth muscle cells. Pediatr Res 60: 657-662, 2006.

33. Lu D, Xie S, Sukkar MB, Lu X, Scully MF and Chung KF: Inhibition of airway smooth muscle adhesion and migration by the disintegrin domain of ADAM-15. Am J Respir Cell Mol Biol 37: 494-500, 2007.

34. Walker TR, Moore SM, Lawson MF, Panettieri RA Jr and Chilvers ER: Platelet-derived growth factor-BB and thrombin activate phosphoinositide 3 -kinase and protein kinase B: Role in mediating airway smooth muscle proliferation. Mol Pharmacol 54: 1007-1015, 1998.

35. Zheng YB, Xiao GC, Tong SL, Ding Y, Wang QS, Li SB and Hao ZN: Paeoniflorin inhibits human gastric carcinoma cell proliferation through up-regulation of microRNA-124 and suppression of PI3K/Akt and STAT3 signaling. World J Gastroenterol 21: 7197-7207, 2015. 